\title{
Field Performance of Grafted Fruit-Tree Rootstocks Was Not Affected by Micropropagation
}

\author{
J.A. Marín, M. Castillo, E. García and P. Andreu \\ Estación Experimental de Aula Dei (CSIC). \\ Apartado 202, 50080 Zaragoza (Spain).
}

Keywords: Prunus $\times$ amygdalopersica, $P$. insititia, crop production, vigor, fruit weight, yield, fruit quality, fruit color.

\begin{abstract}
The use of micropropagated trees has been widely extended, since micropropagation is a convenient technique of vegetative propagation that shows a number of interesting advantages, mainly for woody fruit trees. However, only few studies can be found in the literature on the field performance of micropropagated trees. In this work, the performance of different micropropagated fruit-tree rootstocks, grafted with some peach and nectarine varieties, was compared with grafted rootstocks propagated by conventional methods. The Prunus rootstocks 'Adafuel', 'Adarcias' (both, almond $x$ peach hybrids) and 'Adesoto 101' show different problems when propagated by conventional techniques that reduce the propagation rate, including: low percentage of rooting ('Adesoto 101', 'Adarcias'), roots of bad quality ('Adarcias'), excessive vigor in the nursery and uneven growth ('Adafuel'). However, micropropagation solved these problems supplying uniform plants with good behavior and size in the nursery. Both plant types, micropropagated or cutting-derived plants, were grafted with different varieties: 'Adafuel' and 'Adarcias' were grafted with the varieties 'Baby Gold 5', and 'Super Crimson Gold', and 'Adesoto 101' with 'Catherine' and the selection NJC 97. After one year of growth in the nursery, suitable trees were planted in the field. Data obtained during the first years of field growth suggest that the rootstock propagation method did not seem to influence the field performance of fruit trees, since no remarkable differences were observed, for each combination rootstock/scion, between the different propagation methods for any of the observed characters: crop production, vigor, fruit weight, yield, and fruit quality (soluble solids concentration - SSC, pH, acidity, firmness) and color.
\end{abstract}

\section{INTRODUCTION}

Micropropagation is the most extended application of tissue culture techniques, being more important with woody fruit tree species due to different reasons including their long live, their need of vegetative propagation and their frequent lack of rooting capability. Fruit trees are usually formed by a combination of two individuals, the rootstock and the scion, that are propagated by different means. While scions are grafted in suitable rootstocks, rootstocks have to be propagated vegetatively; however, conventional methods (cuttings and layering among others) are not able, in many cases, to give a satisfactory response, and then, rootstock micropropagation is the method of choice. The use of micropropagated trees has been widely extended, since micropropagation is a convenient technique of vegetative propagation that shows a number of advantages. Applied to different Prunus rootstocks, micropropagation 
increased the rooting capability of difficult-to-root clones as 'Adesoto 101' and 'Adarcias'; improved root quality of 'Adarcias'; as well as reduced the excessive vigor of 'Adafuel', with uneven growth in the nursery . Thus, solving different problems present when propagated by conventional techniques, and supplying uniform plants with good behavior and size in the nursery.

However, only few studies can be found in the literature on the field performance of micropropagated trees. Recently, it has been stated that the performance of micropropagated, own-rooted, Japanese persimmon trees was affected by the initial growing environment, the use of potted plants being better than that of plants raised in an outdoor nursery (Tetsumura et al., 1998). In addition, plant size of own-rooted micropropagated peach trees affected positively the initial performance after planting; however, budded trees increased in size faster than micropropagated own-rooted plants (Hammerschlag and Scorza, 1991). Budded trees seem to present advantages in apple compared to micropropagated, own-rooted varieties (Zimmerman and Steffens, 1995). Studies with micropropagated rootstocks showed only small differences in vigor (Navatel and Bourrain, 1994), but a higher presence in apple of undesirable burrknots (Webster and Jones, 1992). In spite of these studies, the behavior of micropropagated rootstocks, when grafted and planted in the field, has not been evaluated.

In this work, the performance of different micropropagated fruit-tree rootstocks, grafted with some peach and nectarine varieties, was compared with grafted rootstocks propagated by conventional methods in order to ascertain the suitability of micropropagation for commercial orchards.

\section{MATERIALS AND METHODS}

\section{Plant material, Treatments, and Statistics}

The Prunus rootstocks 'Adafuel', 'Adarcias' (both almond $x$ peach hybrids, Prunus $x$ amygdalopersica), and 'Adesoto 101' ( $P$. insititia), propagated by micropropagation and by cuttings, were used. Micropropagation was achieved from axillary buds taken from field-grown plants in a modified MS (Murashige and Skoog, 1962) medium (Castillo and Marín, 1994). Shoots were rooted in the same medium without cytokinins and acclimatized in a plastic tent in the greenhouse in Jiffy-pots with a peat-vermiculite (1:1) substrate. Plants were trasplanted to pots and later to a frame outdoors until they were planted in the nursery. Micropropagated and cutting-derived plants were grafted with different varieties. 'Adafuel' and 'Adarcias' were grafted with the varieties 'Baby Gold 5' and 'Super Crimson Gold', whereas 'Adesoto 101' with both 'Catherine' and the selection NJC 97.

Grafted trees were planted in 1995 at The Estación Experimental de Aula Dei, Zaragoza, Spain, after one year of growth in the nursery, at a frame of $5 \mathrm{~m} \mathrm{x} 4 \mathrm{~m}$. Trees were trained to the vase system. Fruits from the first two crops (1999 and 2000) were collected and analyzed. Three similar trials, one for each rootstock, were performed. The design was a randomized complete block where a tree served as an experimental unit. Each block contained four rootstock-variety combinations (treatments), combining for each rootstock the type of propagation and the varieties. Treatments were replicated eight times. Production (kg per tree), fruit weight (g), trunk cross-sectional area $\left(\mathrm{cm}^{2}\right)$, and yield $\left(\mathrm{kg} \cdot \mathrm{cm}^{-2}\right)$ data were recorded. Mean comparison was conducted by the Student- $\mathrm{t}$ test. 


\section{Fruit Quality and Color}

Fruit skin color was measured only in 2000 (three fruits per tree) with a Minolta Chroma Meter (Model CR-200) as CIE (Commission Internationale de I'Eclairage) 1976 $\mathrm{L}^{*}, \mathrm{a}^{*}$, and $\mathrm{b}^{*}$ that represents (from negative to positive): $\mathrm{L}^{*}$, dark to bright; $\mathrm{a}^{*}$, green to red; b*, blue to yellow. Firmness was measured (three fruits per tree) with a Bertuzzi Penetrometer (Fruit Tester FT327). Fruit juice was obtained by mixing three fruits per tree. Soluble solids concentration (SSC) of the fruit juice was measured with an Atago Digital Refractometer (Palette PR-101). Juice $\mathrm{pH}$ was measured with a Sentron digital pH-meter (pH-System 1001). Titratable acidity (TA\%) was measured by titration of $1 \mathrm{ml}$ of juice with $0.1 \mathrm{~N} \mathrm{NaOH}$ with phenolphthalein (0.5\%) and a digital Witeg Titrex 2000. Mean comparison was also conducted by the Student-t test.

\section{RESULTS AND DISCUSSION}

Data presented here suggest that the method of propagation of the rootstock did not seem to influence the field performance of the fruit trees, since no remarkable differences were observed, for each combination rootstock/scion, between the different propagation methods. Variability between the first two crops is present in almost all parameters but they are easily explained in terms of variable environmental conditions, and different ripening degree at cropping time.

There were no statistical differences in fruit crop expressed as kilograms per tree within each year (Table 1). Micropropagated rootstocks showed a slight increment in relation to cutting-derived rootstocks in almost all cases, however this increment was not statistically significant. The mean fruit weight presented more variable values, and only in the case of Super Crimson Gold / 'Adarcias', in 1999, showed significant differences that favored the micropropagation method; however, this difference was not maintained in the next crop. Vigor, expressed as the trunk cross-sectional area of the tree, showed similar values except for the more vigorous rootstock 'Adafuel' grafted with Baby Gold 5. In this case, micropropagated trees showed less vigor but with similar fruit crop, increasing the yield. These differences were statistically significant both in 1999 and 2000. Micropropagation would be of interest in some vigorous combinations provided these differences would be maintained during the next years.

The type of propagation of the rootstocks did not affect fruit quality parameters (Table 2). There were no significant differences in SSC, and $\mathrm{pH}$. Acidity showed significant differences only for the rootstock 'Adarcias' in 1999 when grafted with 'Baby Gold 5'; however, these differences were not maintained in 2000. Main differences in firmness for 'Super Crimson Gold' between 1999 and 2000 crops revealed that fruits were collected at a different degree of fruit ripening; however, the type of propagation did not affect firmness except for the rootstock 'Adesoto 101' grafted with the selection NJC97, and only in 2000.

Fruit color was not affected, in a remarkable way, by the rootstock propagation method either. There were not differences in the extent of the red blush, nor in the color parameters $\mathrm{L}^{*}$ and $\mathrm{b}^{*}$ for any treatment combination tested. It was only found a significant difference for 'Adesoto 101' grafted with the selection NJC97 in the parameter $\mathrm{a}^{*}$, indicating that fruit color was more greenish when the rootstock was propagated by cuttings; thus favoring the micropropagation method. However, the values of the $\mathrm{a}^{*} / \mathrm{b} *$ index are very close to zero in both cases due to the predominant yellowish color of the fruits. 
From the data presented here it can be concluded that the rootstock propagation method did not have a remarkable effect on fruit crop and quality of any of the six combinations variety/rootstock tested, thus, making micropropagation a very useful way to avoid problems present when conventional methods are used.

\section{ACKNOWLEDGEMENTS}

This work has been funded in part by grants CICYT AGF98-0277-C4-01, and CONSI+D-DGA P54/98. We acknowledge the technical assistance of M.C. Jiménez, A. Almudí, J. Pérez and J. Aparicio.

\section{Literature Cited}

Castillo, M. and Marín, J.A. 1994. Enraizamiento in vivo de patrones frutales micropropagados. Información Técnica Económica Agraria vol. extra 15: 138-144.

Hammerschlag, F.A. and Scorza, R. 1991. Field performance of micropropagated, ownrooted peach trees. J. Amer. Soc. Hort. Sci. 116: 1089-1091.

Murashige, T. And Skoog, F. 1962. A revised medium for rapid growth and bioassays with tobacco tissue cultures. Physiol. Plant. 15: 473-479

Navatel, J.C. and Bourrain, L. 1994. Influence of the physical structure of the medium on in vitro rooting. Adv. Hort. Sci. 8: 57-59.

Tetsumura, T., Yukinaga, H. and Tao, R. 1998. Early field performance of micropropagated Japanese persimmon trees. HortScience 33: 751-753.

Webster, C.A. and Jones, O.P. 1992. Performance of field hedge and stoolbed plants of micropropagated dwarfing apple rootstock clones with different degrees of apparent rejuvenation. J. Hort. Sci. 67: 521-528.

Zimmerman, R.H. and Steffens, G.L. 1995. Cultivar, planting density, and growth regulator effects om growth and fruiting of tissue cultured apple trees. J. Amer. Soc. Hort. Sci. 120: 183-193. 


\section{$\underline{\text { Tables }}$}

Table 1. Effect of the rootstock propagation type on different parameters of the different rootstock/variety combinations (Production, Fruit Weight, Trunk Cross-Sectional Area -TCSA, and Yield). P: rootstock propagation type; m: micropropagation; c: cuttings; ${ }^{*}{ }^{* *}$ indicate significant differences within means of each combination and year at the $5 \%$ or $1 \%$ level respectively.

\begin{tabular}{|c|c|c|c|c|c|c|c|c|}
\hline \multirow[b]{2}{*}{ Year } & \multicolumn{2}{|c|}{$\begin{array}{c}\text { Production } \\
\text { kg.tree-1 }\end{array}$} & \multicolumn{2}{|c|}{$\begin{array}{c}\text { Fruit Weight } \\
\text { g }\end{array}$} & \multicolumn{2}{|c|}{$\begin{array}{c}\text { TCSA } \\
\mathrm{cm}^{2}\end{array}$} & \multicolumn{2}{|c|}{$\begin{array}{c}\text { Yield } \\
\mathrm{kg} \cdot \mathrm{cm}^{-2}\end{array}$} \\
\hline & 1999 & 2000 & 1999 & 2000 & 1999 & 2000 & 1999 & 2000 \\
\hline 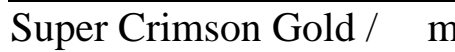 & 24.7 & 19.8 & 97.9 & 98.0 & 75.2 & 85.3 & 0.33 & 0.23 \\
\hline Adafuel c & 22.4 & 19.1 & 100.8 & 98.7 & 75.2 & 86.3 & 0.30 & 0.23 \\
\hline Super Crimson Gold / & 17.9 & 13.8 & $87.4^{*}$ & 96.8 & 54.6 & 62.6 & 0.33 & 0.22 \\
\hline Adarcias c & 12.0 & 10.4 & $79.1^{*}$ & 121.6 & 38.1 & 44.7 & 0.27 & 0.22 \\
\hline Baby Gold 5 / Adafuel m & 33.6 & 16.6 & 181.5 & 159.0 & $70.6^{*}$ & $80.2^{*}$ & $0.48^{* *}$ & $0.34^{*}$ \\
\hline C & 30.3 & 16.1 & 189.3 & 170.9 & $81.3^{*}$ & $92.9^{*}$ & $0.37^{* *}$ & $0.26^{*}$ \\
\hline Baby Gold 5 / Adarcias m & 20.5 & 16.8 & 175.7 & 154.0 & 52.2 & 59.0 & 0.39 & 0.40 \\
\hline C & 18.9 & 15.3 & 170.5 & 149.9 & 51.8 & 59.9 & 0.36 & 0.34 \\
\hline Catherine / Adesoto $101 \mathrm{~m}$ & 13.8 & 15.2 & 146.1 & 157.5 & 48.4 & 61.6 & 0.29 & 0.25 \\
\hline c & 13.5 & 14.3 & 139.1 & 159.0 & 49.9 & 60.7 & 0.27 & 0.24 \\
\hline JC97 / Adesoto 101 & 5.4 & 9.7 & 128.3 & 205.8 & 35.5 & 43.1 & 0.14 & 0.23 \\
\hline C & 5.4 & 8.0 & 137.9 & 292.4 & 32.5 & 39.0 & 0.17 & 0.20 \\
\hline
\end{tabular}

Table 2. Effect of the rootstock propagation type on different parameters of fruit quality of the different rootstock / variety combinations (Soluble Solids Concentration -SSC, $\mathrm{pH}$, Acidity, Firmness). P: rootstock propagation type; m: micropropagation; c: cuttings; ${ }^{*}$ indicates significant differences within means of each combination and year at the $5 \%$ level; ${ }^{+}$indicates that firmness is expressed as $\mathrm{kg} \cdot \mathrm{cm}^{-2}$.

\begin{tabular}{|c|c|c|c|c|c|c|c|c|}
\hline \multirow[t]{2}{*}{$\mathrm{P}$} & \multicolumn{2}{|c|}{$\begin{array}{l}\text { SSC } \\
{ }^{\circ} \text { Brix }\end{array}$} & \multicolumn{2}{|c|}{$\mathrm{pH}$} & \multicolumn{2}{|c|}{$\begin{array}{l}\text { Acidity } \\
\text { meq. } \mathrm{l}^{-1}\end{array}$} & \multicolumn{2}{|c|}{$\begin{array}{l}\text { Firmness } \\
\mathrm{kg} \cdot 0.5 \mathrm{~cm}^{-2}\end{array}$} \\
\hline & 1999 & 2000 & 1999 & 2000 & 1999 & 2000 & 1999 & 2000 \\
\hline \multirow{2}{*}{$\begin{array}{r}\text { Super Crimson Gold / } \\
\text { Adafuel }\end{array}$} & 11.3 & 15.6 & 3.46 & 3.82 & 120.1 & 155.0 & $2.18^{+}$ & $6.20^{+}$ \\
\hline & 11.0 & 15.1 & 3.45 & 3.86 & 121.4 & 147.5 & $2.16^{+}$ & $5.10^{+}$ \\
\hline \multirow{2}{*}{$\begin{array}{r}\text { Super Crimson Gold / } \\
\text { Adarcias }\end{array}$} & 11.2 & 15.3 & 3.44 & 3.74 & 144.8 & 176.3 & $2.01^{+}$ & $6.41^{+}$ \\
\hline & 11.6 & 15.7 & 3.51 & 3.65 & 126.0 & 168.6 & $1.97^{+}$ & $4.47^{+}$ \\
\hline \multirow[t]{2}{*}{ Baby Gold 5 / Adafuel } & 12.5 & 14.2 & 3.55 & 4.15 & 108.0 & 97.3 & 2.62 & 2.11 \\
\hline & 12.4 & 13.8 & 3.55 & 4.16 & 109.5 & 99.1 & 2.66 & 2.14 \\
\hline \multirow[t]{2}{*}{ Baby Gold 5 / Adarcias } & 12.2 & 13.1 & $3.55^{*}$ & 4.08 & $118.0^{*}$ & 96.0 & 2.15 & 1.76 \\
\hline & 12.4 & 13.3 & $3.63^{*}$ & 4.13 & $105.0^{*}$ & 90.4 & 1.88 & 1.53 \\
\hline \multirow[t]{2}{*}{ Catherine / Adesoto $101 \mathrm{n}$} & 13.9 & 14.3 & 3.46 & 4.17 & 133.5 & 125.0 & 3.02 & 2.44 \\
\hline & 13.5 & 13.2 & 3.49 & 4.13 & 126.8 & 120.0 & 3.05 & 2.52 \\
\hline \multirow[t]{2}{*}{ NJC97 / Adesoto 101} & 11.5 & 11.6 & 3.51 & 3.80 & 122.0 & 152.5 & 2.07 & 3.61 \\
\hline & 12.4 & 11.6 & 3.54 & 3.79 & 117.8 & 161.3 & 1.73 & 4.23 \\
\hline
\end{tabular}


Table 3. Effect of the rootstock propagation type on different parameters of fruit color of some rootstock / variety combinations in 2000 (\% Red Blush, CIE -Commission Internationale de I'Eclairage- $1976 \mathrm{~L}^{*}$, $\mathrm{a}^{*}$, and $\mathrm{b}^{*}$ ). P: rootstock propagation type; m: micropropagation; c: cuttings; ${ }^{*}$ indicates significant differences within means of each combination at the $5 \%$ level.

\begin{tabular}{|c|c|c|c|c|c|}
\hline$P$ & $\begin{array}{l}\text { \% Red } \\
\text { Blush }\end{array}$ & $L^{*}$ & $\mathrm{a}^{*}$ & $b^{*}$ & $\begin{array}{l}\mathrm{a} * / \mathrm{b} * \\
\text { index }\end{array}$ \\
\hline \multirow{2}{*}{$\begin{array}{r}\text { Super Crimson Gold / } \\
\text { Adafuel }\end{array}$} & - & 37.02 & 33.95 & 15.05 & 2.49 \\
\hline & - & 38.10 & 34.13 & 16.43 & 2.42 \\
\hline \multirow{2}{*}{$\begin{array}{r}\text { Super Crimson Gold / } \\
\text { Adarcias }\end{array}$} & - & 38.51 & 32.83 & 15.80 & 2.35 \\
\hline & - & 41.57 & 30.20 & 19.51 & 2.13 \\
\hline \multirow[t]{2}{*}{ Baby Gold 5 / Adafuel } & 41.7 & - & - & - & - \\
\hline & 42.9 & - & - & - & - \\
\hline \multirow{2}{*}{ Baby Gold 5 / Adarcias m } & 45.8 & - & - & - & - \\
\hline & 43.3 & - & - & - & - \\
\hline \multirow{2}{*}{$\begin{array}{r}\text { Catherine / Adesoto } 101 \mathrm{~m} \\
\mathrm{c}\end{array}$} & 16.5 & 70.40 & 9.00 & 59.70 & 0.15 \\
\hline & 19.6 & 70.80 & 10.50 & 60.20 & 0.18 \\
\hline \multirow[t]{2}{*}{ NJC97 / Adesoto 101} & 42.7 & 68.40 & $3.65^{*}$ & 53.61 & $0.07^{*}$ \\
\hline & 35.4 & 68.84 & $-1.02^{*}$ & 52.25 & $-0.02^{*}$ \\
\hline
\end{tabular}

